\title{
PENGEMBANGAN SENSOR KECEPATAN ANGIN UNTUK EARLY WARNING SYSTEM BAHAYA ANGIN KENCANG DI JEMBATAN SURAMADU
}

\author{
Ebid Rocky Alfatikh ${ }^{1}$ \\ ${ }^{1}$ SPINS Interactional School \\ Karangan Jaya III No.1, Wiyung, Surabaya, Jawa Timur 60228 \\ ${ }^{1}$ Program Magister Pendidikan Geografi, Sekolah Pascasarjana, UNESA, \\ Jl. Lidah Wetan, Lakarsantri, Surabaya, Jawa Timur 60213
}

\begin{abstract}
Abstrak: Jembatan Suramadu memiliki peran penting untuk mempercepat pembangunan di Pulau Madura. Meningkatnya ketergantungan masyarakat terhadap Jembatan Suramadu maka keamanan jembatan harus ditinjau agar pengguna jembatan dapat terlindung dari bahaya. Salah satu aspek dalam keamanan dan keselamatan jembatan adalah aliran udara di jembatan terutama angin samping (crosswind). Pada bulan Januari 2012 Jembatan Suramadu sudah ditutup sebanyak 11 kali akibat angin kencang. Oleh sebab itu diperlukan suatu sistem peringatan dinisebelum kejadian angin kencang tersebut terjadi agar pihak pengelola dan masyarakat dapat mempersiapkan diri menghadapi kejadian tersebut.serta mendapat informasi yang faktual dan cepat untuk menghindari korban jiwa. Jenis penelitian yang digunakan adalah penelitian kuantitatif dengan metode eksperimental. Hasil penelitian menunjukkan alat anemometer yang terintegrasi dengan arduino efektif untuk mendapatkan informasi factual, akurat dan bersifat kontinyu untuk early warning systemterjadinya angin kencang di jembatan suramadu harus cepat di teruskan kepada pengguna yang hendak masuk suramadu karena untuk menghindari terjadinya hantaman angin kencang ketika berada di dalam jembatan suramadu.
\end{abstract}

Kata kunci :Sensor angin, early warning system, angin kencang

\section{A. PENDAHULUAN}

Jembatan Suramadu yang mulai beroperasi pada tanggal 10 Juni 2010 adalah jembatan yang menghubungkan Pulau Jawa dan Pulau Madura. Tujuan dibangunnya jembatan ini adalah untuk mempercepat pembangunan di Pulau Madura. Oleh karena meningkatnya ketergantungan masyarakat terhadap Jembatan Suramadu maka keamanan jembatan harus ditinjau agar pengguna jembatan dapat terlindung dari bahaya. Salah satu aspek dalam keamanan dan keselamatan jembatan adalah aliran

\footnotetext{
Alamat korespondensi :

E-mail :ebidgeografi91@gmail.com
}

udara di jembatan terutama angin samping (crosswind) (Kusumo, 2012).

Angin kencang diatas jembatan dapat menyebabkan kecelakaan dan membahayakan pengguna jembatan. Struktur jembatan sendiri juga dapat berpengaruh pada aliran udara di sekitar jembatan (Xu dan Guo, 2004). Pada bulan Januari 2012 Jembatan Suramadu sudah ditutup sebanyak 11 kali akibat angin kencang. Oleh sebab itu diperlukan suatu sistem peringatan dini atau early warning sebelum kejadian angin kencang tersebut terjadi agar pihak pengelola dan 
masyarakat dapat mempersiapkan diri menghadapi kejadian tersebut, serta mendapat informasi yang faktual dan cepat untuk menghindari korban jiwa.

Untuk mendeteksi kecepatan angin bisa dikembangkan sensor anemometer yang dipadukan dengan arduino sehingga menghasilkan data yang bisa langsung diteruskan ke masyrakat. Anemometer adalah alat yang digunakan untuk mengukur kecepatan angin. Satuan dari kecepatan angin adalah Knots (Skala Beaufort) dan dapat juga dalam m/s. Alat pengukur kecepatan angin dikatakan baik jika memberikan hasil pengukuran yang lebih akurat. Pembuatan alat pengukur kecepatan angin dapat memanfaatkan teknologi mikrokontroler. (Derek dkk 2016)

Sama halnya dengan sistem komputer, mikrokontroler mempunyai kemampuan untuk diprogram sesuai dengan kebutuhan pembuatan alat pengukur kecepatan angin. Berdasarkan latar belakang diatas maka peneliti melakukan penelitian dengan judul "Pengembangan Sensor Kecepatan Angin untuk Early Warning System bahaya angin kencang di Jembatan Suramadu".

\section{B. METODE}

Dalam melakukan penelitian ini, jenis penelitian yang digunakan adalah penelitian kuantitatif dengan metode eksperimental. Dipilihnya jenis penelitian ini karena peneliti merasa jenis ini cocok dengan penelitian yang diangkat yaitu merancang dan membangun sebuah prototype dan melakukan penelitian berupa eksperimen terhadap objek penelitian penulis. Adapun lokasi penelitian ini dilakukan di Jembatan Suramadu. Alat yang dibutuhkan dalam penelitian ini yakni:

\section{1) Hardware yang digunakan :}

-Mikrokontroler Arduino Uno, Sensor optocoupler, DI-Smart LCD 2x16, Wireless NRF24L01, Modul step up dcdc xl6009, Batteray 9v, Batteray 6v, Panel surya 1wp, Pipa plastic, Bola pimpong, Pipa, Box, Sambungan pipa, Kabel, Specer, Mur dan baut, Saklar on/off.

2) Sofware yang digunakan :

- Sofware Arduino dan Microsoft office 2010.

Perancangan alat monitoring kecepatan angin dengan koneksi wireless memerlukan konsep yang baik agar bisa menghasilkan alat yang bisa berfungsi dengan baik dan akurat. 


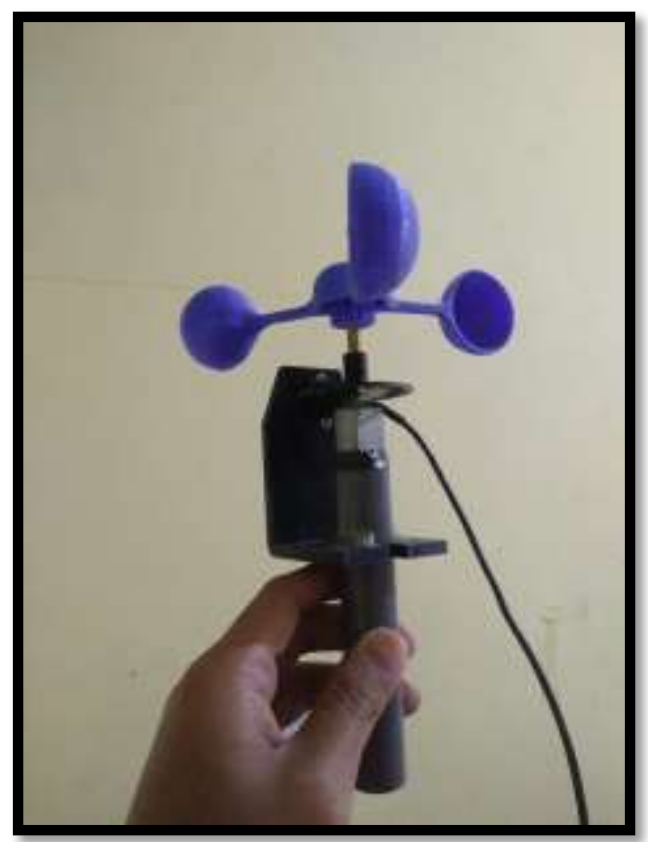

Gambar 1. Sensor Anemometer

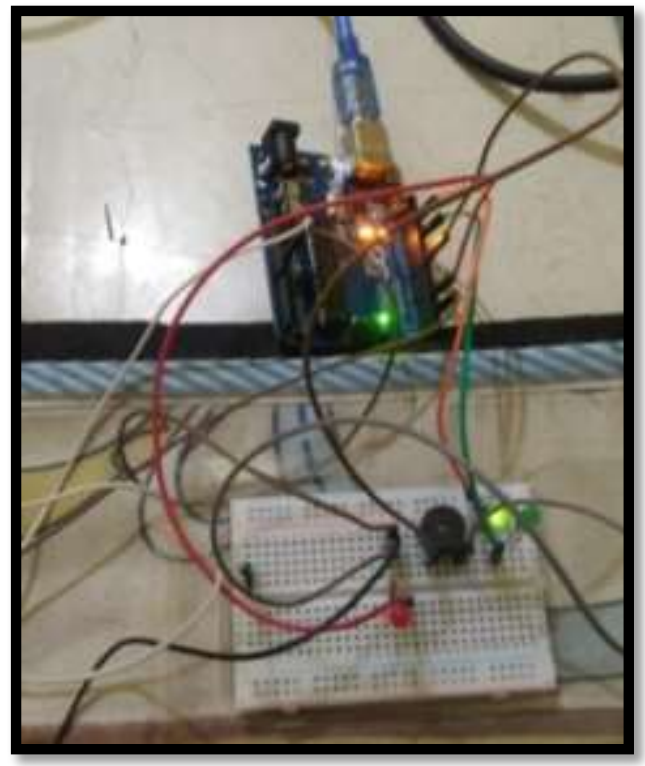

Gambar 2. Arduino yang dikoneksikan ke Anemometer

Dalam perancangan sistem alat ini terdiri dari perancangan alat keras (hardware) dan perangkat lunak (software). Perangkat keras dalam perancangan alat yang akan dibangun meliputi mikrokontroler Arduino Uno.
Berikut ini merupakan penjelasan secara umum dalam perancangan alat secara keseluruhan yang dapat dilihat pada gambar 2.

Pengukur kecepatan angin terdiri dari sensor berupa baling-baling mangkok yang terhubung dengan piringan berlubang, dan sensor optocoupler. Baling-baling mangkok terhubung dengan piringan berlubang yang digunakan untuk menghtung kecepatan putar balingbaling mangkok tersebut. Titik pusat piringan dan titik pusat baling-baling mangkok dihubungkan dengan sebuah poros, sehingga piringan berputar sesuai dengan kecepatan baling-baling pada mangkok.

Prinsip kerja anemometer yang terhubung melalui arduino yaitu sensor mengubah besaran kecepatan angin menjadi sinyal digital. Sinyal ini diolah oleh suatu rangkaian elektronik optocoupler yang terdiri dari photodioda data diolah oleh piranti Mikrokontroller Arduino uno.Metode pengerjaan penelitian ini terbagi sebagai berikut:

1. Perancangan latar belakang proposal berdasarkan masalah yang tingginya urgensinya di masyarakat.

2. Pembelian hardware dan softwareHardware berupa kabel jumper, resistor, led 3 warna hijau merah kuning, 
board practical, dan buzzerSoftware berupa software arduino yang sifatnya open source.

3. Perancangan panel anemometer yang dikoneksikan dengan arduino

4. Koding di software arduino.

Metode pengolahan data dalam penelitian ini yaitu:

1) Reduksi Data adalah mengurangi atau memilah-milah data yang sesuai dengan topik dimana data tersebut dihasilkan dari penelitian.

2) Koding data adalah penyusuaian data diperoleh dalam melakukan penelitian kepustakaan maupun penelitian lapangan dengan pokok pada permasalahan dengan cara memberi kode-kode tertentu pada setiap data tersebutKoding data dalam penelitian ini menggunakan formula IF ELSE di program arduino. Berikut koding dari proyek ini:

// Pin definitions

\# define windPin $2 / /$

\# define buzzer 8 //

\# define led 4 //

\# define led2 7 //

\# define led3 12 //

// Constants definitions

const float $\mathrm{pi}=3.14159265 ; / /$ pi number int period = 1000; // Measurement period (miliseconds)

int delaytime $=1000 ; / /$ Time between samples (miliseconds)

int radio $=80$; // Distance from center windmill to outer cup (mm)

int jml_celah $=22$; // jumlah celah sensor
// Variable definitions

unsigned int Sample $=0$; // Sample number

unsigned int counter $=0 ; / / \mathrm{B} / \mathrm{W}$ counter for sensor

unsigned int RPM = 0; // Revolutions per minute

float speedwind $=0$; // Wind speed $(\mathrm{m} / \mathrm{s})$

void setup()

\{

// Set the pins

pinMode(windPin, INPUT);

pinMode(buzzer, OUTPUT);

pinMode(led, OUTPUT);

pinMode(led2, OUTPUT); $\backslash$

pinMode(led3, OUTPUT); $\backslash$

digitalWrite(2, HIGH);

// sets the serial port to 9600

Serial.begin(9600);

// Splash screen

Serial.println("ANEMOMETER

EBID");

Serial.println("BY EBID");

Serial.println("HASIL

PENGUKURAN");

Serial.println();

\}

void loop()

\{ short duration, windspeed;

if ( speedwind $>2$ )

digitalWrite(buzzer, HIGH);

else if (speedwind <2)

digitalWrite(buzzer, LOW);

if ( speedwind $>2$ )

digitalWrite(led, HIGH);

else if (speedwind <2)

digitalWrite(led, LOW);

if ( speedwind $>=1$ and speedwind $<2$ )

digitalWrite(led2, HIGH);

if (speedwind <1)

digitalWrite(led3, HIGH);

else if (speedwind $>=1$ )

digitalWrite(led3, LOW);

Sample++;

Serial.print(Sample); 
Serial.print(": Start measurement...");

windvelocity();

Serial.println(" finished.");

Serial.print("Counter: ");

Serial.print(counter);

Serial.print("; RPM: ");

RPMcalc();

Serial.print(RPM);

Serial.print("; Wind speed: ");

WindSpeed();

Serial.print(speedwind);

Serial.print(" [m/s]");

Serial.println();

delay(10);

\}

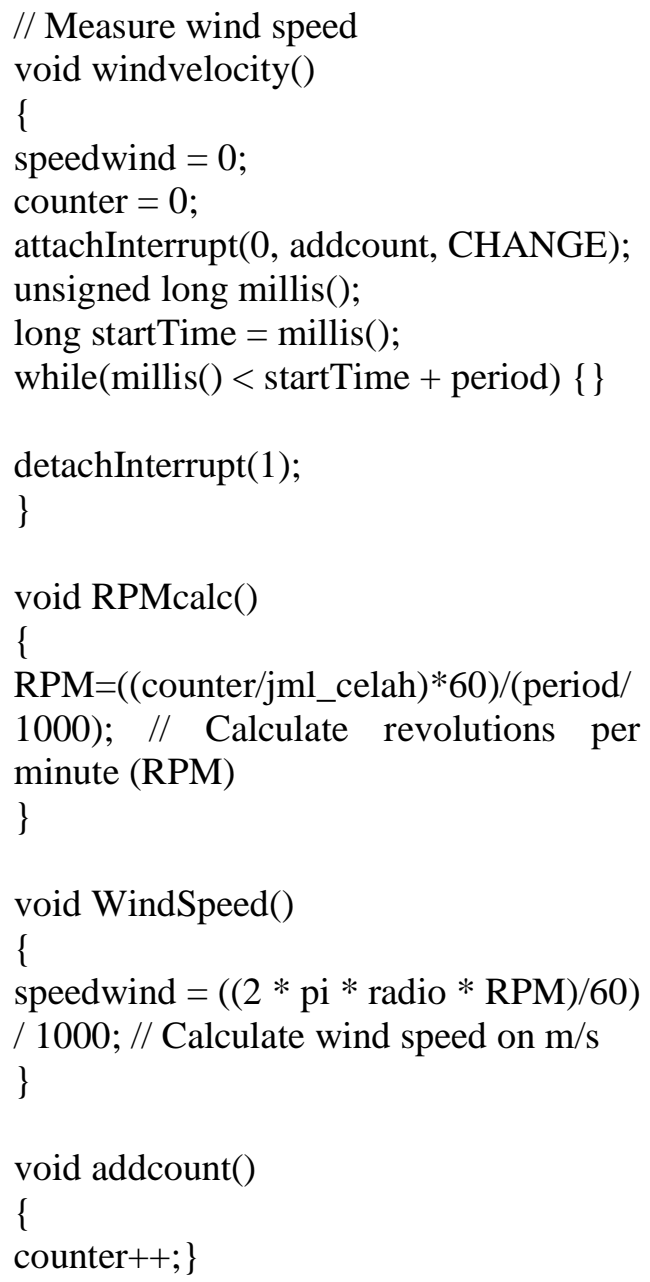

Teknik analisis data bertujuan menguraikan dan memecahkan masalah yang berdasarkan data yang diperoleh.
Analisis yang digunakan adalah analisis data kualitatif. Analisis data kualitatif adalah upaya yang dilakukan dengan jalan mengumpulkan, memilah-milah, mengklasifikasikan, dan mencatat yang dihasilakan catatan lapangan serta memberikan kode agar sumber datanya tetap dapat ditelusuri.Ketika angin berada pada level amanmaka lampu led warna hijau menyala. Ketika angin berada pada level siaga maka lampu led warna hijau menyala. Ketika angin berada pada level awas maka lampu led merah dan buzzer menyala

\section{HASIL DAN PEMBAHASAN}

Pengembangan Sistem pengukuran mempunyai peranan penting dalam kehidupan manusia, khususnya untuk mengetahui nilai dari besaran fisis. Pengukuran adalah membandingkan besaran fisis yang belum diketahui nilainya dengan besaran fisis yang telah diketahui nilainya. Hasil pengukuran bersifat universal yang dapat dinyatakan dalam angka dan satuan atau nilai dan satuan, misalnya pengukuran kecepatan, berat, suhu dan lain-lain.

Kecepatan termasuk dalam
pengukuran tunggal, yang hanya
mungkin dilakukan satu kali saja karena
obyek pengukuran tidak dapat diulang.

Alat ukur yang digunakan dapat 
memakai berbagai macam alat, sesuai dengan fungsi penggunaannya, dalam bahasan ini untuk mengukur kecepatan angin.

Perkembangan teknologi saat ini telah sampai pada penggunaan satelit di skala makro. Satelit dapat digunakan untuk mempelajari pembentukan awan, suhu dan perkiraan cuaca, sedangkan dalam skala mikro dapat digunakan untuk mendeteksi kecepatan angin atau suhu di daerah tertentu. Namun pemanfaatan satelit dalam skala mikro, misalnya untuk mendeteksi kecepatan angin, belum dapat diandalkan.

Parameter keamanan Jembatan Suramadu saat ini ditentukan oleh kecepatan angin yang terukur di Stasiun Maritim BMKG Tanjung Perak. Stasiun Maritim BMKG Tanjung Perak berjarak kurang lebih $4 \mathrm{Km}$ dari Jembatan Suramadu.

Parameter keselamatan yang digunakan saat ini oleh pihak Badan Pengembangan Wilayah Suramadu (BPWS) adalah ketika kecepatan angin di Stasiun Maritim BMKG Tanjung Perak mencapai $40 \mathrm{~km} / \mathrm{jam}$ atau $11.1 \mathrm{~m} / \mathrm{s}$ maka jembatan akan ditutup untuk pengendara sepeda motor. Sedangkan ketika kecepatan angin mencapai $60 \mathrm{~km} / \mathrm{jam}$ atau $16.67 \mathrm{~m} / \mathrm{s}$ maka jembatan akan ditutup sepenuhnya baik sepeda motor maupun mobil. (Taufiq 2012)

Selain itu juga bisa melalui pengembangan data Cross-Calibrated Multi-Platform (CCMP) yang sudah diuji kemampuannya untuk penggambaran kasus kejadian penutupan jembatan. Pada tahun 2011 Atlas dkk. melakukan penelitian mengenai akurasi CCMP yang digunakan untuk pencitraan kecepatan angin permukaan laut. Hasil dari penelitian ini menunjukan bahwa perbedaan nilai atau selisih antara data CCMP dan data pengamatan insitu di daerah laut sebesar $0.5 \mathrm{~m} / \mathrm{s}$. Penelitian ini menunjukan bahwa data CCMP memiliki akurasi yang cukup baik untuk digunakan sebagai data verifikasi. (Atlas 2011)

Namun data dari BMKG maupun data dari CCMP merupakan data sekunder dan data yang bersifat probably. Salah satu upaya untuk mengatasi kendala tersebut adalah dengan pembuatan alat ukur otomatis. Alat ukur yang digunakan harus bersifat peka, kuat, sederhana dan teliti. Secara garis besar ada dua macam metode dalam pembacaan alat ukur, yaitu: - Recording yaitu alat yang dapat mencatat data secara terusmenerus, sejak pemasangan hingga pergantian alat berikutnya. Contoh : barograf dan anemograf - Non recording yaitu alat yang digunakan bila 
datanya harus dibaca pada saat-saat tertentu untuk memperoleh data. Contoh: barometer, ermometer dan anemometer.

Hasil penelitian menunjukkan alat anemometer yang terintegrasi dengan arduino efektif untuk mendapatkan informasi faktual dan akurat untuk early warning system erjadinya angin kencang di jembatan suramadu harus cepat di teruskan kepada pengguna yang hendak masuk suramadu karena untuk menghindari terjadinya hantaman angin kencang ketika berada di dalam jembatan suramadu.

\section{SIMPULAN}

Penggunaan teknologi untuk mendeteksi bahaya angin samping di wilayah suramadu masih menganlkan data sekunder dari bmkg, sehingga masyarakat tidak secara cepat dan kontinyu menerima sinyal tersebut.

Berdasarkan hasil pengujian dari simulasi sistem peringatan dini bahaya angin kencang, dapat disimpulkan bahwa tujuan dari penelitian ini telah tercapai, yaitu memberikan informasi sedini mungkin akan adanya bahaya angin kencang kepada pengunjung yang berada disekitar pintu masuk jembatan Suramadu. Karena alat yang dikembangkan di proposal ini memiliki karakteristik yang mumpuni untuk early warning system, Adapun saran yang dapat disampaikan peneliti yaitu:

1. Diharapkan alat sistem ini bisa dibuat dalam bentuk real dengan mengacu pada prototype yang telah dibuat oleh peneliti.

2. Untuk hasil yang maksimal diharapkan menggunakan sensor pembacaan arus yang lebih bagus agar data yang diperoleh juga akurat.

\section{DAFTAR PUSTAKA}

ANTARA. Jembatan Suramadu di Tutup Akibat Angin Kencang. Oktober 2, 2010.

http://www.mediaindonesia.com/read/20 $\underline{10 / 10 / 02 / 17}$

2377/125/101/Jembatan-Suramadu-

Ditutup-akibat- Angin-Kencang (accessed Juni 5, 2012).

Atlas, Robert, et al. "A Cross-Calibrated, Multiplatform Ocean Surface Wind Velocity Product For Meteorological And Oceanographic Applications ." American Meteorology Society, 2011: 157174.

Badan Pengembangan Wilayah Surabaya Madura. Suramadu Percepat Pemberdayaan Ekonomi Madura. 2 12, 2012. http://bpws.go.id/?p=894 (accessed 6 2, 2012). 
Derek,Oktavian dkk. 2016. Rancang Bangun Alat Monitoring Kecepatan Angin Dengan Koneksi Wireless Menggunakan Arduino Uno. EJournal Teknik Elektro dan Komputer vol.5 no.4 Juli-September 2016. UNSRAT:Manado.

F. Djuandi, 21 Juli 2011[online]. "pengenalan arduino". Tersedia di:www.tokobuku.com

Kusumo, Bimo. 2012. Prediksi Aliran Udara Di Jembatan Suramadu Dengan Model WRF-CFD. Program Studi Meteorologi Institut Teknologi Bandung. Bandung.

Taufiq, Fatkhurrohman. Ada Puting Beliung, Jalur Motor Suramadu Ditutup. Maret 13, 2012. http://www.tempo.co/read/news/201 2/03/13/058389 905/Ada-PutingBeliung-Jalur-Motor-SuramaduDitutup (accessed mei 7, 2019) Zhou, Qi, Le-Dong Zhu, and Zhen-Shan Guo. "Study on wind environment over a bridge deck near tower using CFD with LES model and wind tunnel test." The Fifth International Symposium on Computational Wind Engineering. Chapel Hill, 2010. 